\title{
Achados vestibulares em pacientes portadores de fibromialgia
}

\author{
Vestibular findings in fibromyalgia patients
}

\author{
Bianca Simone Zeigelboim ${ }^{1}$, Denise Nunnes Moreira². \\ 1) Doutor em Distúrbios da Comunicação Humana pela UNIFESP/EPM. Professor Adjunto do Curso de Fonoaudiologia, Coordenador do Programa de Pós-Graduação \\ em Distúrbios da Comunicação e Responsável pelo Setor de Vestibulometria da Universidade Tuiuti do Paraná. \\ 2) Especialista em Audiologia Clínica pela Universidade Tuiuti do Paraná \\ Instituição: Laboratório de Otoneurologia da Universidade Tuiuti do Paraná (UTP). \\ Curitiba / PR - Brasil. \\ Endereço para correspondência: Bianca Simone Zeigelboim - Rua Gutemberg, 99 - 9ª andar - Curitiba / PR - Brasil - CEP: 80420-030 - Telefone: (+55 41) 3331-7807 \\ -E-mail: bianca.zeigelboim@utp.br \\ Artigo recebido em 14 de Dezembro de 2010. Artigo aprovado em 27 de Março de 2011
}

\section{RESUMO}

Introdução: A fibromialgia (FM) é uma síndrome musculoesquelética não inflamatória, de caráter crônico, de etiologia desconhecida, caracterizada por dor difusa, aumento da sensibilidade na palpação e por sintomas como fadiga, insônia, ansiedade, depressão, intolerância ao frio e queixas otológicas.

Objetivo: Avaliar o comportamento vestibular em pacientes portadores de fibromialgia.

Método: Foi realizado um estudo retrospectivo de corte transversal. Avaliaram-se 25 pacientes na faixa etária entre 26 e 65 anos (média de idade - 52,2 anos e desvio padrão - 10,3 anos), submetidos aos seguintes procedimentos: anamnese, avaliação otorrinolaringológica e vestibular por meio da vectoeletronistagmografia.

Resultados: a) Os sintomas otoneurológicos mais evidenciados foram: dificuldade ou dor ao movimento do pescoço e dor irradiada para ombro ou braço $(92,0 \%)$ em cada, tontura $(84,0 \%)$ e cefaleia $(76,0 \%)$. Os sintomas clínicos diversos mais relatados foram: depressão $(80,0 \%)$, ansiedade $(76,0 \%)$ e insônia (72,0\%); b) O exame vestibular esteve alterado em 12 pacientes (48,0\%) sendo localizado na prova calórica; c) Houve prevalência de alteração no sistema vestibular periférico e, d) Houve predomínio das disfunções vestibulares periféricas deficitárias.

Conclusão: Este estudo permitiu verificar a importância do exame labiríntico o que ressalta que esse tipo de população deveria ser melhor estudada, uma vez que diversas doenças reumatológicas pelas suas manifestações e áreas de comprometimento podem gerar alterações vestibulares importantes. Palavras-chave: fibromialgia, tontura,t estes de função vestibular, eletronistagmografia.

\section{SUMMARY}

Introduction: Fibromyalgia (FM) is a non-inflammatory musculoskeletal chronic syndrome, whose etiology is unknown, characterized by a diffuse pain, increase in palpation sensitivity and such symptoms as tiredness, insomnia, anxiety, depression, cold intolerance and otologic complaints.

Objective: Evaluate the vestibular behavior in fibromyalgia patients.

Method: A retrospective transversal study was performed. 25 patients aged between 26 and 65 (average age -52.2 and standard deviation-10.3) were evaluated and submitted to the following procedures: anamnesis, otorhinolaryngologic and vestibular evaluation by way of vector electronystamography.

Results: a) The most evident otoneurologic symptoms were: difficulty or pain when moving the neck and pain was spread to an arm or shoulder (92.0\%) in each, dizziness (84.0\%) and headache (76.0\%). The different clinical symptoms mostly reported were: depression (80.0\%), anxiety (76.0\%) and insomnia (72.0\%); b) vestibular examination showed an alteration in 12 patients (48.0\%) in the caloric test; c) an alteration in the peripheral vestibular system prevailed, and d) deficient peripheral vestibular disorders were prevalent.

Conclusion: This study enabled the importance of the labyrinthic test to be verified, thus emphasizing that this kind of people must be studied better, since a range of rheumatologic diseases can cause severe vestibular changes as a result of their manifestations and impairment areas.

Keywords: fibromyalgia, dizziness, vestibular function tests, electronystagmography. 


\section{INTRODUÇÃO}

A fibromialgia (FM) é uma síndrome musculoesquelética não inflamatória, de caráter crônico, de etiologia desconhecida, caracterizada por dor difusa, aumento da sensibilidade na palpação e por sintomas como fadiga, insônia, ansiedade, depressão, intolerância ao frio e queixas otológicas. Embora os mecanismos fisiológicos que controlam a FM não tenham sido estabelecidos, fatores neuroendócrinos, genéticos ou moleculares podem estar envolvidos (1,2).

Pesquisas recentes revelam anormalidades bioquímicas, metabólicas e imunorreguladora. O mecanismo mais aceito para o entendimento fisiopatológico da FM é o de uma alteração em algum mecanismo central de controle da dor o qual poderia resultar em uma disfunção neuro-hormonal. Tal disfunção incluiria uma deficiência de neurotransmissores inibitórios em níveis espinais ou supraespinais (serotonina, encefalina, norepinefrina, etc), ou uma hiperatividade de neurotransmissores excitatórios (substância P, glutamato, bradicinina e outros peptídeos), ou ambas as condições poderiam estar presentes. Essas disfunções poderiam ser desencadeadas por uma infecção viral, estresse mental ou por um trauma físico e poderiam ser pré-determinadas geneticamente (1).

Diversas anormalidades têm sido observadas nos portadores de FM, dentre elas, ressaltam-se: a) liberação da substância P (neuro-hormônio) em níveis elevados no líquido cerebroespinal; b) deficiência de serotonina nas plaquetas; c) nível baixo de trifosfato de adenosina; d) metabolismo anormal de carboidratos nas hemáceas; e) regulação anormal da produção de cortisol e, f) diminuição de fluxo sanguíneo em determinadas estruturas cerebrais (3).

A influência de mecanismos genéticos ou moleculares podem estar envolvidos. Diversos estudos têm abordado a frequência em diversos familiares de paciente com FM, sugerindo que estes fatores podem desempenhar papel relevante em sua etiopatogenia (2).

Pesquisas recentes demonstram que a frequência de polimorfismos dos genes catecol-O-metiltransferase (COMT) com genótipo L/L foi maior em pacientes com FM, o que indica que este genótipo produz uma enzima defeituosa incapaz de metabolizar as catecolaminas do sistema de maneira eficaz. Apesar da FM envolver uma situação poligênica e fatores ambientais, o estudo molecular pode auxiliar na identificação de indivíduos suscetíveis (2).

Muitas tentativas para elucidar a patogenia orgânica da FM, têm sido realizadas na última década, pesquisas em genética, aminas biogênicas, neurotransmissores, hormônios do eixo hipotálamohipófise-adrenal, estresse oxidativo, mecanismos de modulação da dor, sensibilização central e função autonômica na FM, revelam várias anormalidades, indicando que múltiplos fatores e mecanismos podem estar envolvidos na patogênese dessa doença (4).

Estudos demonstram haver uma falta de regulação nosistema nervoso autônomo na FMe discute a disautonomia como um potencial mecanismo participante na gênese e manutenção da sintomatologia e comorbidades (4).

Alvares e Lima (5) e Martinez et al. (6), referem que a sobrecarga ocupacional constitui um importante fator etiológico, podendo ser precedida pelos distúrbios osteomusculares relacionados ao trabalho (DORT/LER).

Pesquisas revelam que diversos sintomas da FM podem ser confundidos com os decorrentes pelas reações hansênicas e que ambas as doenças podem ocorrer concomitantemente (7). Além disso, referem que portadores de FM podem apresentar um nível elevado de hormônio estimulador da tireoide (TSH) indicando associação com hipotireoidismo $(8,9)$.

A prevalência da FMé de aproximadamente $2 \%$ da população geral; sendo responsável por $15 \%$ das consultas em ambulatórios de reumatologia, e 5\% a 10\% nos ambulatórios de clínica geral. A proporção de mulheres para homens é de aproximadamente 6 a 10:1. A maior prevalência encontra-se na faixa etária entre 30-50 anos podendo ocorrer na infância e na terceira idade $(1,10)$.

O diagnóstico da FM de acordo com critérios estabelecidos pelo Colégio Americano de Reumatologia, em 1990 estão expostos abaixo (1):

a) dor difusa com duração no mínimo de três meses nas seguintes regiões: dor nos lados esquerdo e direito do corpo, dor acima e abaixo da linha da cintura, dor no esqueleto axial (coluna cervical ou torácica anterior, ou coluna torácica, ou coluna lombar). A dor no ombro ou na nádega é considerada como dor para cada lado envolvido;

b) dor em pelo menos 11 dos 18 pontos palpados denominados "tender points" com uma força aproximada de $4 \mathrm{~kg}$. Para que um "tender point" seja considerado positivo, o paciente deve declarar que a palpação foi dolorosa. A presença dos pontos dolorosos é o achado primordial do exame físico.

Distúrbios na função oculomotora são relatados na FM e podem ocorrer em razão da disfunção nos mecanismos responsáveis pela sua regulação em consequência da diminuição do suprimento sanguíneo no labirinto (11). 
Diversas doenças reumatológicas pelas suas manifestações e áreas de comprometimento, podem gerar alterações vestibulares, sendo os testes otoneurológicos ferramentas importantes na confirmação dos distúrbios vestibulares e suas relações com o sistema nervoso central (SNC) (12).

O objetivo do presente estudo foi avaliar o comportamento vestibular em pacientes portadores de fibromialgia.

\section{MÉTODO}

Avaliaram-se, 25 pacientes do sexo feminino, portadoras de FM na faixa etária de 26 a 65 anos, (média de idade de 52,2 anos; desvio padrão de 10,3 anos), encaminhados do Ambulatório de Reumatologia da Universidade Federal do Paraná (HC-UFPr), para o Setor de Otoneurologia de uma Instituição na cidade de Curitiba/PR.

Trata-se de um estudo transversal e os pacientes foram avaliados independentes do tipo e tempo de tratamento.

Incluiu-se na pesquisa, indivíduos com diagnóstico de fibromialgia sem patologias de orelha média. Excluiu-se da pesquisa, indivíduos que apresentaram alteração otológica ou outras anormalidades que impossibilitasse a realização do exame.

A pesquisa foi aprovada pelo Comitê de Ética Institucional protocolo no. 0187/2009 e após autorização através da assinatura do Termo de Consentimento Livre e Esclarecido, os pacientes foram submetidos aos seguintes procedimentos:

Os pacientes foram submetidos aos seguintes procedimentos:

\section{Anamnese}

Aplicou-se um questionário com ênfase aos sinais e sintomas otoneurológicos, antecedentes pessoais e familiares.

\section{Avaliação Otorrinolaringológica}

Realizada com o objetivo de excluir qualquer alteração que pudesse interferir no exame.

\section{Avaliação Vestibular}

Os pacientes foram submetidos às seguintes provas que compõem o exame vestibular:

Inicialmente, pesquisou-se a vertigem e os nistagmos de posição/posicionamento, espontâneo e semi-espontâneo.

A seguir, para a realização da vectoeletronistagmografia utilizou-se um aparelho termossensível, com três canais de registro, da marca Berger, modelo VN316. Colocaram-se, fixados com pasta eletrolítica, um eletródio ativo no ângulo lateral de cada olho e na linha média frontal, formando um triângulo isósceles, que permite a identificação dos movimentos oculares horizontais, verticais e oblíquos e principalmente, para o cálculo da velocidade angular da componente lenta do nistagmo (VACL).

Utilizou-se uma cadeira rotatória pendular decrescente da marca Ferrante, um estimulador visual modelo EV VEC e um otocalorímetro a ar modelo NGR 05, ambos da marca Neurograff.

Realizaram-se as seguintes provas oculares e labirínticas à VENG, de acordo com critérios propostos pelos autores Mangabeira-Albernaz et al. (13).

- Calibração dos movimentos oculares, nesta etapa do exame, o aspecto clínico avaliado foi à regularidade do traçado, tornando as pesquisas comparáveis entre si.

- Pesquisa dos nistagmos espontâneo (olhos abertos e fechados) e semi-espontâneo (olhos abertos). Nesse registro avaliaram-se a ocorrência, direção, efeito inibidor da fixação ocular (EIFO) e o valor da VACL máxima do nistagmo.

- Pesquisa do rastreio pendular para a avaliação da ocorrência e do tipo de curva.

- Pesquisa do nistagmo optocinético, à velocidade de $60^{\circ}$ por segundo, nos sentidos anti-horário e horário, na direção horizontal. Avaliaram-se a ocorrência, direção, VACL máxima às movimentações anti-horária e horária do nistagmo.

- Pesquisa dos nistagmos pré e pós-rotatórios à prova rotatória pendular decrescente, estimulando-se os ductos semicirculares laterais, anteriores e posteriores. Para a estimulação dos ductos semicirculares laterais (horizontais) a cabeça foi fletida $30^{\circ}$ para frente. Na etapa seguinte, para a sensibilização dos ductos semicirculares anteriores e posteriores (verticais) o posicionamento da cabeça foi de $60^{\circ}$ para trás e $45^{\circ}$ à direita e, a seguir, $60^{\circ}$ para trás e $45^{\circ}$ à esquerda, respectivamente. Observaram-se a ocorrência, direção, frequência às rotações anti-horária e horária do nistagmo.

- Pesquisa dos nistagmos pré e pós-calóricos, realizada com o paciente posicionado de forma que a cabeça e o tronco estivessem inclinados $60^{\circ}$ para trás, para estimulação adequada dos ductos semicirculares laterais. O tempo de irrigação de cada orelha com ar a $42^{\circ} \mathrm{C}$ e $20^{\circ} \mathrm{C}$ durou 80 s para cada temperatura e as respostas foram registradas com os olhos fechados e, a seguir, com os olhos abertos para a observação do EIFO. Nesta avaliação observaram-se a direção, os valores absolutos da VACL e o cálculo das relações da preponderância 
direcional e predomínio labiríntico do nistagmo pós-calórico.

\section{Análise Estatística}

Aplicou-se o Teste de Diferença de Proporções com a finalidade de comparar os resultados do exame vestibular (analisando os resultados normais e alterados) e o Teste de Fischer (correlacionando os resultados do exame vestibular com desequilíbrio à marcha e zumbido). Fixou-se 0,05 ou 5\% o nível de rejeição na hipótese de nulidade.

\section{RESULTADOS}

A frequência dos sinais e sintomas otoneurológicos em pacientes com FM encontra-se na Tabela 1.

A frequência de sinais clínicos diversos poderão ser observados na Tabela 2 .

A pesquisa do nistagmo posicional não foi realizada por impossibilidade física das pacientes e as seguintes provas; calibração dos movimentos oculares, pesquisa dos nistagmos espontâneos de olhos abertos e fechados, semiespontâneo, rastreio pendular e do nistagmo optocinético não evidenciaram alterações.

À prova calórica, ocorreram cinco casos (20,0\%) de hiporreflexia labiríntica bilateral, três casos $(12,0 \%)$ de hiperreflexia labiríntica unilateral, dois casos $(8,0 \%)$ de predominância labiríntica (PL) assimétrica, um caso (4,0\%) de hiporreflexia labiríntica unilateral e um caso $(4,0 \%)$ de hiperreflexia labiríntica bilateral. Em treze casos (52,0\%) o exame esteve dentro dos padrões de normalidade (normorreflexia), conforme demonstra a Tabela 3.

Em doze casos (48,0\%) ocorreram disfunções vestibulares periféricas, sendo oito casos (32,0\%) de disfunção vestibular periférica deficitária e quatro casos $(16,0 \%)$ de disfunção vestibular periférica irritativa. O exame vestibular foi normal em treze casos (52,0\%), conforme Tabela 4 .

À aplicação do Teste de Proporções, comprova que não existe diferença significativa entre as proporções dos exames normais e alterados $(\mathrm{p}=0,7785)$.

A Correlação entre o resultado do exame vestibular e a presença de desequilíbrio à marcha, poderá ser observada na Tabela 5 .

À aplicação do Teste de Fischer, comprova que existe diferença significativa entre as proporções de pacientes com exame vestibular normal (EVN) e exame vestibular alterado (EVA) com e sem a presença de desequilíbrio à marcha $(\mathrm{p}=0,0131)$.
Tabela I. Distribuição da frequência dos sinais e sintomas otoneurológicos em pacientes com fibromialgia.

\begin{tabular}{lcc}
\hline Sinaise Sintomas & N & Frequência \\
Otoneurológicos & & \\
\hline Dificuldade ou dorao movimento do pescoço & 23 & $92,0 \%$ \\
Dorirradiada para ombro ou braço & 23 & $92,0 \%$ \\
Tontura & 2 I & $84,0 \%$ \\
Cefaleia & I & $76,0 \%$ \\
Desequilíbrioàmarcha & I2 & $48,0 \%$ \\
Zumbido & II & $44,0 \%$ \\
Sensação de cabeça oca & II & $44,0 \%$ \\
Estalono pescoço & 8 & $32,0 \%$ \\
Náusea & 8 & $32,0 \%$ \\
Sensação deflutuação & 6 & $24,0 \%$ \\
Palidez & 6 & $24,0 \%$ \\
Formigamento deextremidade & 6 & $24,0 \%$ \\
Escurecimento de visão & 5 & $20,0 \%$ \\
Palpitação & 5 & $20,0 \%$ \\
Sudorese & 5 & $20,0 \%$ \\
Sensação que vaidesmaiar & 4 & $16,0 \%$ \\
Vômitos & 4 & $16,0 \%$ \\
Formigamento daface & 3 & $12,0 \%$ \\
\hline
\end{tabular}

N- número de casos

Tabela 2. Outros achados clínicos em pacientes com fibromialgia.

\begin{tabular}{lcc}
\hline Sinaise Sintomas Clínicos Diversos & N & Frequência \\
\hline Depressão & 20 & $80,0 \%$ \\
Ansiedade & 19 & $76,0 \%$ \\
Insônia & 18 & $72,0 \%$ \\
Fadiga & 16 & $64,0 \%$ \\
Agitação durante o sono & 9 & $36,0 \%$ \\
Medo & 3 & $12,0 \%$ \\
\hline
\end{tabular}

N- número de casos

Tabela 3. Resultados obtidos na prova calórica analisando os valores absolutos e relativos em pacientes com fibromialgia.

\begin{tabular}{lcc}
\hline Prova Calórica & N & Frequência \\
\hline Normorreflexia & 13 & $52,0 \%$ \\
Hiporreflexialabirínticabilateral & 5 & $20,0 \%$ \\
Hiperreflexialabiríntica unilateral & 3 & $12,0 \%$ \\
Predominância labirínticaassimétrica & 2 & $8,0 \%$ \\
Hiporreflexia labiríntica unilateral & 1 & $4,0 \%$ \\
Hiperreflexialabirínticabilateral & I & $4,0 \%$ \\
\hline
\end{tabular}

N- número de casos

Tabela 4. Resultados do exame vestibular em pacientes com fibromialgia.

\begin{tabular}{lcc}
\hline Resultados & N & Frequência \\
\hline E.V.N & 13 & $52,0 \%$ \\
D.V.P.D & 8 & $32,0 \%$ \\
D.V.P.I. & 4 & $16,0 \%$ \\
\hline
\end{tabular}

Legenda: N - número de casos; E.V.N. - exame vestibular normal; D.V.P.D - disfunção vestibular periférica deficitária; D.V.P.I - disfunção vestibular periférica irritativa. 
Tabela 5. Correlação entre o resultado do exame vestibular e a presença de desequilíbrio à marcha em vinte e cinco pacientes com fibromialgia

\begin{tabular}{lccc}
\hline Exame & \multicolumn{2}{c}{$\begin{array}{c}\text { Sintoma } \\
\text { Não }\end{array}$} & Sim \\
\hline E.V.N. & 10 & 3 & $P$ \\
E.V.A. & 3 & 9 & $0,\left.013\right|^{*}$ \\
\hline
\end{tabular}

Legenda: E.V.N. - exame vestibular normal; E.V.A. - exame vestibular alterado.

À aplicação do Teste de Fischer, considerando-se o nível de significância de 5\% (á=0,05), comprova que existe diferença significativa entre as proporções de pacientes com exame vestibular normal (EVN) e exame vestibular alterado (EVA) com e sem a presença de desequilíbrio à marcha, pois $\mathrm{p}=0,0131$

A Correlação entre o resultado do exame vestibular e a presença de zumbido, poderá ser observada na Tabela 6.

À aplicação do Teste de Fischer, comprova que existe diferença significativa entre as proporções de pacientes com EVN e EVA com e sem zumbido ( $p=0,0002)$.

\section{DISCUSSÃO}

Na análise da anamnese verificou-se a ocorrência de múltiplos sintomas otoneurológicos e clínicos diversos, dentre os quais podemos citar os de maior prevalência, respectivamente: dificuldade ou dor ao movimento do pescoço e dor irradiada para ombro ou braço $(92,0 \%) \mathrm{em}$ cada, tontura (84,0\%) e cefaleia (76,0\%); depressão (80,0\%), ansiedade (76,0\%) e insônia (72,0\%). Os sintomas são variados e a dor se manifesta nas regiões musculares e periarticulares tornando-se gradualmente generalizada. De acordo com a literatura os sintomas de tontura e zumbido são comumente referidos na FM $(1,2,11,14,15)$. Para HADJDJILANI e GERSTER (15) os sintomas otoneurológicos podem decorrer de anormalidades musculoesqueléticas comuns na FM e estas podem afetar a propriocepção provocando uma sensação de instabilidade.

Jacomini e Silva (4) referem que a correlação entre os sinais e sintomas otoneurológicos e a FMé demonstrada em diversos estudos que revelam haver uma falta de regulação do sistema nervoso autônomo provocando desta forma, a disautonomia. Os autores sugerem que a FMé uma forma generalizada de distrofia simpático-reflexa. Estudos realizados em animais mostram que o trauma pode desencadear hiperatividade simpática constante, os nervos transmissores de dor são alterados e anormalmente ativados pela noradrenalina, o que explicaria o mecanismo conhecido em medicina como dor simpaticamente mantida. Esse
Tabela 6. Correlação entre o resultado do exame vestibular e a presença de zumbido em vinte e cinco pacientes com fibromialgia.

\begin{tabular}{lccc}
\hline Exame & $\begin{array}{c}\text { Sintoma } \\
\text { Não }\end{array}$ & $\begin{array}{c}\text { Sim } \\
\text { Simeurógico }\end{array}$ & $P$ \\
\hline E.V.N. & 12 & 1 & $0,0002 *$ \\
E.V.A. & 2 & 10 & \\
\hline
\end{tabular}

Legenda: E.V.N. - exame vestibular normal; E.V.A. - exame vestibularalterado.

tipo de dor é caracterizada por instalação pós-trauma, por sua independência a qualquer dano tissular e pela presença de alodinia. Para os autores, a hiporreatividade simpática oferece explicação coerente para a fadiga constante e outros sintomas associados como a vertigem, confusão mental e fraqueza.

Investigações genômicas emergentes vêm contribuindo para elucidar a participação do sistema simpático na FM. A catecol-O-metiltransferase (COMT) é uma enzima que inativa catecolaminas e drogas que contenham o grupamento catecol. O gene que codifica a COMT está mapeado e a influência do polimorfismo desse gene vem sendo investigada na busca de elucidar seu envolvimento na patogênese de várias desordens psiquiátricas e na percepção da dor. O significado do polimorfismo do gene que expressa a COMT foi estudado na FM, e, consideraramse três polimorfismos: LL (low/baixo), LH (low/high/intermediário) e HH (high/alto) que determinam a taxa de degradação das catecolaminas ou drogas catecólicas (16).

Gursoy et al. (16) relataram que 73,8\% das mulheres com FM tinham baixa ou intermediária atividade enzimática e 26,2\%, elevada atividade enzimática. Esse resultado, variante LL muito representada e variante $\mathrm{HH}$ pouco representada, resulta em baixa ou elevada degradação de catecolaminas, respectivamente. Isso quer dizer que quanto mais baixa a atividade enzimática, mais catecolamina há no meio. Esses resultados corroboram a ideia de sistema simpático hiperativo na FM e evidenciam o envolvimento do polimorfismo da COMT na FM.

Evidências atuais sustentam a hipótese de um distúrbio na neuromodulação da dor, envolvendo principalmente o SNC.A fisiopatologia proposta está relacionada a um distúrbio primário no mecanismo central do controle da dor em indivíduos com FM, resultante de alterações nos neurotransmissores. A disfunção neuro hormonal incluiria 
deficiência de neurotransmissores inibitórios (serotonina, encefalina, norepinefrina e outros) ou uma hiperatividadedos excitatórios (substância P, glutamato, bradicinina e outros peptídeos), ou as duas situações de modo simultâneo (1).

A deficiência de serotonina contribui para anomalias do sono, depressão e aumento da dor, que influenciam na liberação de substância P. A diminuição dos níveis de triptofano (precursor da serotonina e neuromodulador) e de outros aminoácidos e um aumento de concentração de substância P, endorfinas eácido 5-hidroxiindolacético foram encontrados no sangue e líquor de indivíduos com FM (1).

Com relação à avaliação vestibular, observou-se alteração do sistema vestibular periférico em 12 pacientes, sendo esta alteração localizada na prova calórica, com predomínio das disfunções vestibulares periféricas deficitárias. Rosenhall, Johansson e ORNDAHL (11) referiram presença de nistagmo posicional, nistagmo espontâneo de olhos abertos com e sem fixação ocular, alterações nos movimentos sacádicos, na velocidade do rastreio pendular e presença de hiporeflexia e hiper-reflexia à estimulação calórica. Encontraram 35\% de disfunção do sistema vestibular com envolvimento do SNC. ZEIGelboim et al (12) e BAYAZIT et al. (14) observaram disfunção periférica somente na prova calórica com presença de hipo e hiperreflexias. Comparando as proporções entre os exames normais e alterados não foram evidenciados diferença significativa. Quando comparamos os exames vestibular normal e alterado, com e sem a presença dos sintomas de desequilíbrio à marcha e zumbido obtivemos diferença significativa entre as proporções.

BAYAZIT et al. (17) realizaram o potencial evocado miogênico vestibular-VEMP e observaram alteração significativa no alongamento da latência n 23 e na latência dos interpicos das ondas p13-n23 demonstrando um envolvimento otoneurológico importante deste exame em pacientes portadores de fibromialgia

$\mathrm{Na}$ literatura compulsada com relação à parte otoneurológica encontramos poucos estudos para que pudéssemos confrontar nossos achados.

\section{CONCLUSÃO}

1) Os sintomas otoneurológicos mais evidenciados foram: dificuldade ou dor ao movimento do pescoço e dor irradiada para ombro ou braço $(92,0 \%)$ em cada, tontura $(84,0 \%)$ e cefaleia $(76,0 \%)$. E os sintomas clínicos diversos mais relatados foram: depressão (80,0\%), ansiedade $(76,0 \%)$ e insônia $(72,0 \%)$.

2) A alteração no exame vestibular ocorreu em 48,0\% dos pacientes, sendo localizada na prova calórica.
3) Houve prevalência de alteração no sistema vestibular periférico.

4) Houve predomínio das disfunções vestibulares periféricas deficitárias.

Este estudo permitiu verificar a importância do exame labiríntico o que ressalta que esse tipo de população deveria ser melhor estudada, uma vez que diversas doenças reumatológicas pelas suas manifestações eáreas de comprometimento podem gerar alterações vestibulares importantes.

\section{REFERÊNCIAS BIBLIOGRÁFICAS}

1. Helfenstein M, Feldman D. Síndrome da fibromialgia: características clínicas e associações com ouras síndromes disfuncionais. Rev Bras Reumatol. 2002, 42(1):8-14.

2. Matsuda JB, Barbosa FR, Morel LJF, França ZC, Zingaretti SM, Silva LM, et al. Polimorfismos dos genes do receptor de serotonina (5-HT2A) e da catecol-O-metiltransferase (COMT): fatores desencadeantes da fibromialgia? Rev Bras Reumatol. 2010, 50(2):141-5.

3. Roberto M, Papt TR. Fisiopatologia da fibromialgia. Acta Fisiátrica. 2004, 11(2):78-81.

4. Jacomini LCL, Silva NA. Disautonomia: um conceito emergente na síndrome da fibromialgia. Rev Bras Reumatol. 2007, 47(5):354-61.

5. Alvares TT, Lima MEA. Fibromialgia: interfaces com as LER/DORT e considerações sobre sua etiologia ocupacional. Ciênc. Saúde Coletiva. 2010, 15(3):803-12.

6. Martinez JE, Domingues C, Davolos FJC, Martinez LC, GozzanoJOA. Fibromyalgia patients quality of life and pain intensity variation. Rev Bras Reumatol. 2008, 48(6):325-8.

7. Carneiro SCS. Fibromialgia e reação hansênica. Rev Bras Reumatol. 2006, 46(1):77-9.

8. Rezende LS, Rezende LS, Radominski SC, Paiva ES. A relevância da dosagem do hormônio estimulante da tireoide em pacientes com fibromialgia. Rev Bras Reumatol. 2006, 46(1):73-4.

9. Freire M, Teodoro RB, Oliveira LB, Cunha SFC, Ferreira BP, Borges MF. Concomitância de fibromialgia em pacientes portadores de hipotireoidismo e de alterações tireoideanas em pacientes com fibromialgia. Rev Bras Reumatol. 2006, 46(1):11-5.

10. Provenza JR, PollakDF, MartinezJE, Paiva ES, Helfenstein 
M, Heymann R, et al. Projeto diretrizes - Fibromialgia. Sociedade Brasileira de Reumatologia, 2004. disponível em: http://www.unifesp.br/grupos/fibromialgia/ fibromialgia.pdf.

11. Rosenhall U, Johansson G, Orndahl G. Otoneurologic and audiologic findings in Fibromyalgia. Scand J Rehab Med. 1996, 28:225-32.

12. Zeigelboim BS, Klagenberg KF, Liberalesso PBN, Jurkiewicz AR. Avaliação vestibulococlear na fibromialgia. Rev CEFAC. 2010, 12(4):677-82.

13. Mangabeira-Albernaz PL, Ganança MM, Pontes PAL. Modelo operacional do aparelhovestibular. In: MangabeiraAlbernaz PL, Ganança MM. Vertigem. 2a .ed. São Paulo: Moderna; 1976. p. 29-36.
14. Bayazit YA, Gürsoy S, Özer E, Karakurum G, Madeci E. Neurotologic manifestation of the fibromyalgia syndrome. J Neurootol Sci. 2002, 196:77-80.

15. Hadj-djilani A, Gerster JC. Hearing and vestibular abnormalities in primary fibrosis syndrome Meniere's disease and fibrositis syndrome. J Rheumatol. 1984, 1(5):678-80.

16. Gursoy S, Erdal E, Herken H, Madenci E, Alasehirli B, Erdal N. Significance of catechol-O-methyltransferase gene polymorphism in fibromyalgia syndrome. Rheumatol Int. 2003, 23:104-7.

17. Bayazit YA, Celenk F, Gunduz AG, Gunduz B, Ondag N, Meray J. Vestibular evoked miogenic potentials in patients with fibromyalgia syndrome. J Laryngol Otol. 2010, 124:6105. 